\title{
Turkey-the Hgr Transplant Capital of Europe? Or Just Another Example at 'Switch-Selling!
}

\author{
Malcolm Mendelsohn* \\ High Density Hair Transplants, Greece
}

*Corresponding author: Malcolm Mendelsohn, Athens, Greece

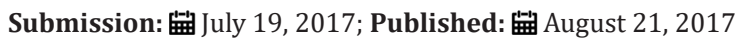

\section{Opinion}

'Switch-Selling'? The Practice of Advertising One Thing \& Supplying Another! Until very recently the questions I was being asked by prospective Hair Transplant clients were generally about my surgeon's experience. How many years has he been operating? How many procedures has he carried out? Is he a member of the GMC (General Medical Council) or the ISHRS (International Society of Hair Restoration Surgery)? The sort of questions one would expect people to ask if they wanted to avoid any of the many pitfalls they could experience from having had a '3rd rate' Hair Transplant procedure. 'Switch-Selling'? The Practice of Advertising One Thing \& Supplying Another! Until very recently the questions I was being asked by prospective Hair Transplant clients were generally about my surgeon's experience. How many years has he been operating? How many procedures has he carried out? Is he a member of the GMC (General Medical Council) or the ISHRS (International Society of Hair Restoration Surgery)? The sort of questions one would expect people to ask if they wanted to avoid any of the many pitfalls they could experience from having had a '3rd rate' Hair Transplant procedure. However, more recently prospective clients seem more concerned about costs than quality and who could blame them? When there are no less than 240 Turkish Hair Transplant Clinics offering them all-inclusive deals for up to a third off the cost of legitimate Hair Transplant operatives.

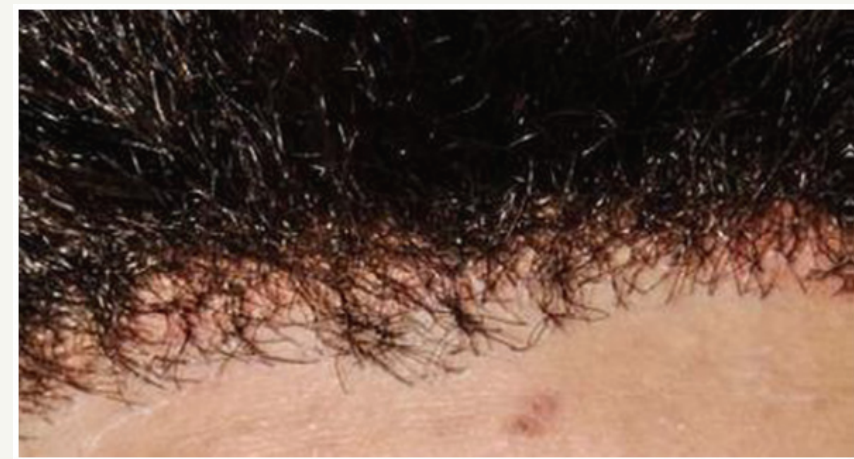

Figure 1: Switch -selling? The practice of advertising one thing \& supplying another.
How do they do it? Easy! Their version of FUE is a very different procedure to that offered by legitimate ISHRS member clinics. For openers, they have scrapped the single most important feature of the FUE (Follicular Unit Extraction) Procedure, the 'Selection' process. The time-consuming process when the Doctor and his team select the hair grafts with the highest numbers of hair content to ensure their patients achieve the best possible density/volume result (Figure 1).

Added to which many of these clinics use young, poorly paid non-medical trainees to 'harvest' the hair grafts. The only time a doctor is consulted is when the patient's hairline is marked out during the initial consultation.

Trainees who pluck out the donor grafts like plucking a chicken. No checking for the higher content hair grafts to give their patients as much volume/density as possible? In recent months, I have had a good few emails from former patients of Turkish clinics, complaining that their hair was growing in the wrong direction!! One guy who called me recently refused to send me his photos and it was only when I saw him on Skype did I understand why? His crown hair was growing straight up! No direction, just straight up. like a turnip!! Planting the new grafts to follow the direction of the patient's original growth takes experience and expertise. Not a job for young trainees.

The Turkish clinic that performed the procedure (pictured above) left their client with scar tissue across his front hairline. Leaving the chances of repairing the damage almost impossible. In fact, it's unlikely anything can be done to help him? The scar tissue will have undoubtedly have compromised his blood supply and fresh grafts will need to be planted deeper, well below the scar tissue to locate fresh blood supply. This can cause even more disastrous results like necrosis.

Along with his photo the unfortunate 'victim' sent me his message: "I had FUE on my hairline two years ago in Istanbul. I regret it now as my hairline looks horrible today. It looks like I have pubic hair on my hairline. I want to have the transplanted hair-plugs "punched" off. I don't mind the white holes that will show up where 
the plugs are planted" The reason for his 'horrible' results is that the clinic concerned had placed the grafts far too close together which breaks the fundamental rules of transplanting. His grafts should have been spaced no closer than $1 \mathrm{~mm}$ apart, the circumference of the graft size themselves. This allows each graft to acquire its own individual blood supply. His grafts literally overlapped one another. Leaving them to fight each other for blood supply. The grafts that won, grew, those that failed withered and died, leaving scar tissue behind.

Only when you Google search 'bad hair transplants in Turkey' will you get a balanced view of what's really going on. They advertise 2000 grafts $=4000$ hairs which, to the uninitiated may seem like a bargain until you understand that 2000 grafts using the 'selection' process can produce up to 5200 hairs. Whereas, the legitimate Hair Transplant clinics using the 'selection' method would have required 1600 grafts to harvest the same 4000 hairs. Saving their patients up to 400 valuable grafts should their patients require further work in the future.

If you enter Hair Transplants into your search engines you will be inundated with deals for surgery in Turkey. You will also be offered testimonials from happy patients. Patients who in the longterm may well find they have insufficient remaining donor grafts to combat their continuing hair loss, due to wasting 'valuable' donor grafts. False Economy! Short Term Gain - Long Term Problems! That's the true picture of Turkey's 'Conveyor Belt' Operators. 'Sour Grapes'? I hear you ask! Can't stand the competition? I don't think so!! Just follow this link and read a totally independent report on the facts of what can happen to those who choose price over experience when considering Hair Transplant Surgery [1].

\section{References}

1. https://www.pressreader.com/uae/the-national-news-busine ss/20161003/281500750747858 